\title{
Review Article \\ Synthetic Cathinones and Their Rewarding and Reinforcing Effects in Rodents
}

\author{
Lucas R. Watterson and M. Foster Olive \\ Department of Psychology, Arizona State University, P.O. Box 871104, Tempe, AZ 85287-1104, USA \\ Correspondence should be addressed to M. Foster Olive; foster.olive@asu.edu
}

Received 12 March 2014; Accepted 16 May 2014; Published 4 June 2014

Academic Editor: Eduardo Puelles

Copyright (C) 2014 L. R. Watterson and M. F. Olive. This is an open access article distributed under the Creative Commons Attribution License, which permits unrestricted use, distribution, and reproduction in any medium, provided the original work is properly cited.

\begin{abstract}
Synthetic cathinones, colloquially referred to as "bath salts," are derivatives of the psychoactive alkaloid cathinone found in Catha edulis (Khat). Since the mid-to-late 2000s, these amphetamine-like psychostimulants have gained popularity amongst drug users due to their potency, low cost, ease of procurement, and constantly evolving chemical structures. Concomitant with their increased use is the emergence of a growing collection of case reports of bizarre and dangerous behaviors, toxicity to numerous organ systems, and death. However, scientific information regarding the abuse liability of these drugs has been relatively slower to materialize. Recently we have published several studies demonstrating that laboratory rodents will readily self-administer the "first generation" synthetic cathinones methylenedioxypyrovalerone (MDPV) and methylone via the intravenous route, in patterns similar to those of methamphetamine. Under progressive ratio schedules of reinforcement, the rank order of reinforcing efficacy of these compounds is MDPV $\geq$ methamphetamine > methylone. MDPV and methylone, as well as the "second generation" synthetic cathinones $\alpha$ pyrrolidinovalerophenone ( $\alpha$-PVP) and 4-methylethcathinone (4-MEC), also dose-dependently increase brain reward function. Collectively, these findings indicate that synthetic cathinones have a high abuse and addiction potential and underscore the need for future assessment of the extent and duration of neurotoxicity induced by these emerging drugs of abuse.
\end{abstract}

\section{The Rise of Synthetic Cathinone Use and Abuse}

In 2007, a new class of designer drugs known as synthetic cathinones emerged in Europe. Soon afterwards, reports of synthetic cathinone use, abuse, toxicity, and death began to surface in USA [1-12]. The rise of synthetic cathinone use in USA was alarmingly rapid, with poison control centers receiving 0,304 , and 6156 calls reporting synthetic cathinone toxicity in the years 2009-2011, respectively [13]. Approximately $98 \%$ of synthetic cathinones first identified in toxicological investigations were primarily 4-methylmethcathinone (4-MMC, mephedrone), 3,4-methylenedioxypyrovalerone (MDPV), and 3,4-methylenedioxymethcathinone (methylone) [1-12], but as discussed below, many additional synthetic cathinones have since surfaced.

Synthetic cathinones are chemical derivatives of cathinone, a naturally occurring amphetamine-like alkaloid found in the Catha edulis (Khat) shrub. Khat has been utilized for centuries by indigenous peoples of the Horn of Africa and Arabian Peninsula for its stimulant properties [14]. However, due to its high abuse liability, cathinone is classified as a Schedule I controlled substance in USA. In an attempt by manufacturers and distributors to evade the attention of regulatory and law enforcement agencies, synthetic cathinones are falsely marketed and sold as innocuous retail products such as "bath salts," "plant food," "research chemicals," and "glass cleaner," to name a few. Synthetic cathinones are also often sold under brand names such as "Ivory Wave" and "Vanilla Sky" and are usually labeled "not for human consumption" or "for research purposes only" [15]. These packages typically consist of one or multiple synthetic cathinones and are often mixed with other substances such as caffeine, topical anesthetics, binding and cutting agents, and even other illicit drugs $[11,16]$. Regardless of the marketing tactic employed, synthetic cathinones are 
ultimately intended for use as "legal high" alternatives to illicit psychostimulants such as cocaine, methamphetamine, and 3,4-methylenedioxymethamphetamine (MDMA, "Ecstasy") [1-12, 17-20].

For synthetic cathinone users, desired psychological effects include increased energy, libido, empathy, euphoria, alertness, and well-being. However, numerous serious adverse effects are associated with synthetic cathinone use [1-12]. Psychological and behavioral complications include confusion, panic, persistent hallucinations and delusions, agitated paranoia, and aggression and violence including suicide, homicide, and infanticide. Synthetic cathinone use is also associated with toxicity of multiple organ systems, sometimes referred to as the "sympathomimetic toxidrome" [7], including chest pain, nausea, vomiting, seizures, hypertension, tachycardia, hyperthermia, cardiac arrest, and death. Despite the high risk of these adverse effects, users of synthetic cathinones frequently report a persistent desire to continue use of these drugs, and prolonged periods of synthetic cathinone use have been reported $[2,3,6,8$, 12, 21-27], suggesting a high potential for addiction and dependence.

\section{Chemistry and Pharmacology of Synthetic Cathinones}

The chemical structure of cathinone is strikingly similar to that of $\mathrm{D}$-amphetamine (Figure 1), with cathinone differing only in the presence of a ketone oxygen atom $(\mathrm{C}=\mathrm{O})$ on the $\beta$ position of the side chain. However, as recently pointed out by Glennon [28], some synthetic cathinones have chemical structures that are entirely novel such that the amphetamine analogs upon which they are based have received little if any scientific study. As mentioned above, during the initial detection of these drugs in USA, approximately $98 \%$ of all synthetic cathinones encountered by law enforcement were either mephedrone, MDPV, or methylone (see Figure 1 for chemical structures). Citing an imminent threat to public health, the U.S. Department of Justice temporarily placed mephedrone, MDPV, and methylone into Schedule I status in October, 2011, which was followed by permanent classification of mephedrone and MDPV as such in August 2012 [29]. Methylone remained under temporary scheduling status pending further collection of data and information and was permanently placed into Schedule I status in April 2013 [30].

Synthetic cathinones are considered "designer drugs" since their chemical structure can be easily altered by as few as one or two atoms to create new chemical entities. Due to the ease with which synthetic cathinones can be chemically modified to create unique chemical entities, over 40 other synthetic cathinones have been identified in clandestine drug markets [28], including the "second generation" synthetic cathinones naphyrone (naphthylpyrovalerone), 3-fluoromethcathinone (3-FMC), methedrone (4-methoxymethcathinone), $\beta$-keto-N-methylbenzodioxolylbutanamine (bk-MBDB, butylone), $\beta$-keto-methylbenzo- dioxolylpentanamine (bk-MBDP, pentylone), 4-methyl-Nethylcathinone (4-MEC), 4-methyl-pyrrolidinopropiophenone (4-MePPP), $\alpha$-pyrrolidinopentiophenone ( $\alpha$-PVP), 2 methylamino-1-phenylpentan-1-one (pentedrone), and 4fluoro-N-methylcathinone (4-FMC, flephedrone). Many of these were placed into temporary Schedule I status in February 2014 while additional data on abuse liability are collected [31].

Synthetic cathinones exert their psychostimulant and sympathomimetic effects either by promoting the release of monoamine neurotransmitters (dopamine, DA; norepinephrine, NE; and serotonin, 5-HT) via reversal of plasma membrane monoamine transporters or by inhibiting the reuptake of monoamines from the synaptic cleft [32-42]. The resulting excessive monoamine levels in the synaptic cleft lead to overstimulation of postsynaptic DA, NE, and 5-HT receptors in the brain and periphery, which results in their psychological, behavioral, and toxic effects. These neuropharmacological actions of synthetic cathinones are remarkably similar to those of more traditional illicit psychostimulants, such as cocaine (a monoamine reuptake inhibitor with high affinity for DA versus other plasma membrane monoamine transporters), D-amphetamine and methamphetamine (monoamine releasers with higher affinity for DA and NE versus 5-HT), and MDMA (a monoamine releaser with a higher affinity for 5-HT versus other plasma membrane monoamine transporters). It is becoming increasingly apparent that, like traditional psychostimulants, different synthetic cathinones have diverse mechanisms of action [28]. For example, mephedrone is a broad spectrum monoamine releasing agent $[32,33,35,38,39,41], \mathrm{MDPV}$ is a long-acting inhibitor of plasma membrane DA and NE transporters [33, $41,43]$, and methylone is a monoamine releasing agent with a higher affinity for plasma membrane 5-HT transporters [32, $38,41]$. Although studies on "second generation" synthetic cathinones are few, thus far it appears that these newer analogues have similar neurochemical actions [38, 41, 44, 45].

\section{Laboratory Rodents Readily Self-Administer MDPV and Methylone}

The intravenous self-administration (IVSA) model is generally considered to be the "gold standard" of preclinical paradigms for assessing the abuse liability of psychoactive compounds. Our laboratory routinely uses this paradigm in rats to assess the potential therapeutic efficacy of pharmacological compounds as potential antiaddiction medications, and we have recently utilized this paradigm to assess the potential abuse liability of synthetic cathinones [46, 47].

In this procedure, first an indwelling intravenous catheter is surgically implanted into the jugular vein while the other end is tunneled under the skin and connected to a vascular access port implanted under the skin and exiting between the scapulae. Following recovery from surgery, the animal is placed in a drug self-administration chamber equipped with two levers that are interfaced with a computer and a syringe pump (see Figure 2). A sterile drug solution (such as MDPV or methylone dissolved in physiological saline) is 
<smiles>CC(N)C(=O)c1ccccc1</smiles>

Cathinone<smiles>CC(N)Cc1ccccc1</smiles>

D-Amphetamine<smiles>CNC(C)Cc1ccccc1</smiles>

Methamphetamine

(a)<smiles>CNC(C)C(=O)c1ccc(C)cc1</smiles>

Mephedrone<smiles>CCCC(C(=O)c1ccc2c(c1)OCO2)N1CCCC1</smiles>

(b)<smiles>CNC(C)C(=O)c1ccc2c(c1)OCO2</smiles>

Methylone<smiles>CCCC(C(=O)c1ccccc1)N1CCCC1</smiles>

$\alpha$-PVP<smiles>CCNC(C)C(=O)c1ccc(C)cc1</smiles>

4-MEC

(c)

FIGURE 1: Similar chemical structures of cathinone, D-amphetamine, and methamphetamine (top row), the "first generation" synthetic cathinones mephedrone, MDPV, and methylone (middle row), and the "second generation" synthetic cathinones $\alpha$-PVP and 4-MEC.
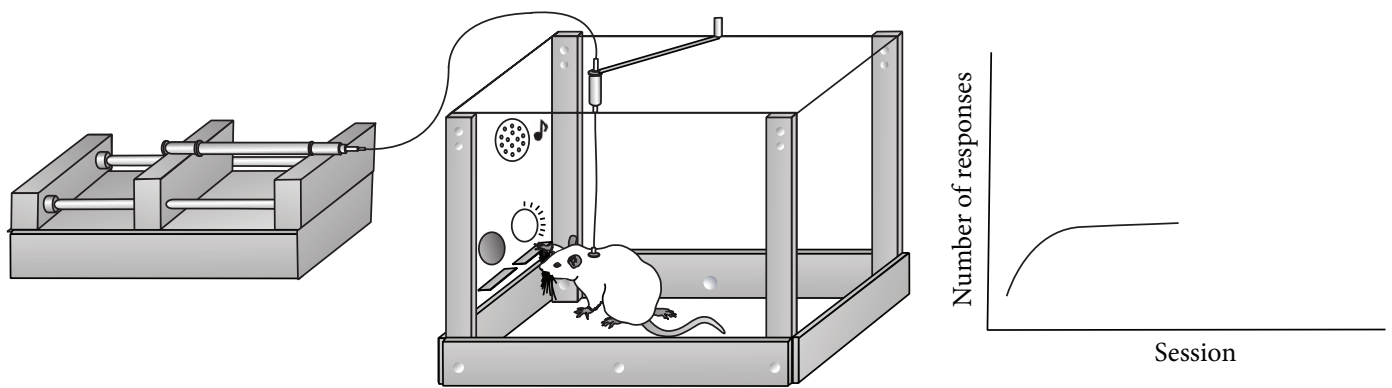

FIGURE 2: The rat intravenous self-administration paradigm for assessment of the abuse liability of synthetic cathinones. Upon pressing of one of two levers (designated the active lever) in an operant self-administration chamber (center), a computer-controlled syringe pump (left) delivers a solution containing MDPV or methylone to an indwelling venous catheter via infusion tubing connected to a liquid swivel. Each drug infusion is accompanied by simultaneous presentation of tone and illumination of a stimulus light located above the lever. Presses on the opposite lever (designated the inactive lever) have no consequences but are recorded to ensure establishment of correct response contingency of drug delivery. The graph on the right represents typical response patterns across daily experimental sessions during the acquisition of drug self-administration.

placed in a syringe and delivered by a computer-controlled syringe pump located outside the apparatus. The syringe is connected to a single-channel liquid swivel, which allows free rotation of the animal while maintaining a continuous flow of the drug solution. In addition to the two response levers, stimulus lights and a speaker provide visual and auditory cues during drug infusions. Presses on one of the levers designated the "active" lever result in a computercontrolled drug infusion and simultaneous brief presentation of auditory and visual cues. Presses on the other "inactive" lever have no programmed consequences at any time during the experiment (as a control for nonspecific behavior). To avoid overdose or toxicity due to multiple drug infusions in close temporal proximity, immediately following each drug infusion a "timeout" period is introduced ( $20 \mathrm{sec})$, whereby additional active lever presses do not result in additional drug infusions. Drug self-administration sessions are typically 2$6 \mathrm{hr}$ in length and are conducted daily, 7 days per week.

There are many advantages of intravenous self-administration procedures as a model for human drug-taking behavior, including the following: (1) the drug is administered voluntarily by the animal (as opposed to passive administration by the experimenter); (2) it is administered directly into the bloodstream mimicking intravenous drug use in humans and results in rapid brain penetrance; (3) drug-taking behavior can be temporally examined within and between self-administration sessions; (4) the effects of candidate therapeutic pharmacological compounds or other experimental manipulations on drug self-administration can be determined; and (5) the number of responses that must 
be exerted by the animal in order to receive a drug infusion (called the "ratio") can be increased exponentially (called a "progressive ratio" procedure) until the animal "gives up" and no longer performs the operant task (called the "breakpoint"). This latter method is used to measure the level of motivation to self-administer the drug as well as the efficacy of the reinforcer. In addition, when given longer daily access (i.e., $6 \mathrm{hr}$ or more per session) to psychostimulants with high addiction potential, rats will gradually and significantly escalate their daily drug intake. This escalated drug intake is a cardinal feature of the transition from drug abuse to addiction, and a sustained enhancement in drug intake produces dysregulated brain stress and executive control systems that parallel clinical observations of drug addicts [48-50]. Moreover, extended access to drugs with lower abuse liability generally do not result in escalation of intake, and drug intake patterns usually remain episodic [51].

Recently, our laboratory has demonstrated robust intravenous self-administration of MDPV and methylone in laboratory rats $[46,47]$. When tested for self-administration of MDPV under limited access conditions (daily sessions that were $2 \mathrm{hr}$ in length), rats readily acquired selfadministration of MDPV at all doses tested $(0.05,0.1$, and $0.2 \mathrm{mg} / \mathrm{kg} /$ infusion). Under a progressive ratio schedule of reinforcement, which requires an exponentially increasing number of lever presses to obtain each subsequent drug infusion within a single test session (i.e., 1 lever press for the first infusion, 2 for the second, 4 for the third, and so on), a positive relationship between MDPV dose and breakpoints for drug reinforcement was observed, suggesting that higher doses of MDPV are associated with increasing reinforcer efficacy and motivation to obtain the drug. By comparison, responding for a low dose of methamphetamine $(0.05 \mathrm{mg} / \mathrm{kg} /$ infusion $)$ produced breakpoints that were similar in magnitude to the same dose of MDPV. When the length of the self-administration session was increased to $6 \mathrm{hr} /$ day, we observed an escalation of drug intake over time for the 0.1 and $0.2 \mathrm{mg} / \mathrm{kg} /$ infusion doses of MDPV, with the highest dose producing the most robust escalation of intake that was similar in magnitude to the $0.05 \mathrm{mg} / \mathrm{kg} /$ infusion dose of methamphetamine. When rats were tested for selfadministration of methylone under limited access conditions [46], rats did not display robust self-administration for the lowest dose of methylone tested $(0.05 \mathrm{mg} / \mathrm{kg} /$ infusion $)$ but readily self-administered higher doses of methylone $(0.1,0.2$, and $0.5 \mathrm{mg} / \mathrm{kg}$ /infusion). However, unlike MDPV, methylone did not lead to escalation of intake under extended access conditions for any dose tested. This is particularly intriguing since methylone is a $\beta$-ketone derivative of MDMA, and self-administration of this parent drug also does not reliably produce escalation of intake under extended access conditions [52-54], which is perhaps also reflective of its preferential affinity for plasma membrane serotonin versus dopamine transporters. Despite the lack of escalation, and underscoring the dangers of synthetic cathinone use, 2 rats in the highest methylone dose group $(0.5 \mathrm{mg} / \mathrm{kg} /$ infusion $)$ self-administered the drug to the point of seizure and death during a $6 \mathrm{hr}$ session, and similar case reports of methylone-induced deaths in humans have been reported
[55-58]. Finally, as with MDPV, we observed a positive relationship between methylone dose and breakpoints for self-administration under progressive ratio conditions. These findings indicate that MDPV and methylone are readily self-administered intravenously by laboratory rats and are in agreement with studies from other laboratories showing that MDPV, as well as the synthetic cathinone mephedrone, is self-administered intravenously by rodents [35, 59-61]. In addition, our studies indicate that escalated intake of synthetic cathinones, a cardinal feature of addiction, can also be observed in laboratory rodents.

\section{Synthetic Cathinones Increase Brain Reward Circuit Function}

It is well accepted that drugs of abuse exert their rewarding (euphorigenic) and reinforcing effects via interactions with brain reward circuitry [62-65]. This circuitry, known as the mesocorticolimbic pathway, is primarily comprised of dopaminergic neurons in the ventral tegmental area (VTA) that project rostrally to form the medial forebrain bundle (MFB) in the lateral hypothalamus and form dopaminergic synapses in forebrain regions including the nucleus accumbens (NAc) and prefrontal cortex (PFC). However, confinement of the neural basis of drug reward and reinforcement to this singular dopaminergic pathway is overly simplistic, as many studies have indicated that other ascending monoaminergic fibers that form the MFB, such as noradrenergic neurons from the locus coeruleus and serotonergic neurons from the raphe nuclei, also contribute to brain reward function [64, 66-69].

A widely used method for assessing functional activity of the brain reward circuitry in behaving animals is the intracranial self-stimulation (ICSS) paradigm [68, 70-73]. In this procedure, which is depicted in Figure 3, a laboratory animal (typically a rat or mouse) performs an operant response such as nose poke, lever press, or rotation of a wheel manipulandum in order to receive a short pulse of electrical current via a chronically implanted electrode into a specific brain region, typically the MFB. The implanted electrode is connected to a computer-controlled current generator via an electrical commutator. The animal quickly learns that the operant response reliably leads to electrical stimulation of the reward circuitry that presumably produces subjective pleasurable effects, and in our experience rats will exert up to several thousand ICSS responses in a $30 \mathrm{~min}$ period $[46,47]$. Different laboratories use a variety of stimulation parameters such as varying the intensity of the current delivered $(\mu \mathrm{A})$, duration of pulses (msec), frequency of electrical pulse as a function of pulse/interpulse interval, and the waveform of pulses [74]. However, the two most extensively used ICSS paradigms in evaluating abuse liability of psychoactive compounds are the rate-frequency curve-shift procedure [75] and the discrete-trial current threshold intensity procedure $[74,76,77]$, the latter of which is utilized by our laboratory $[46,47,51]$.

In the discrete-trials current threshold procedure, following acquisition of operant responding, discrete-trial training 


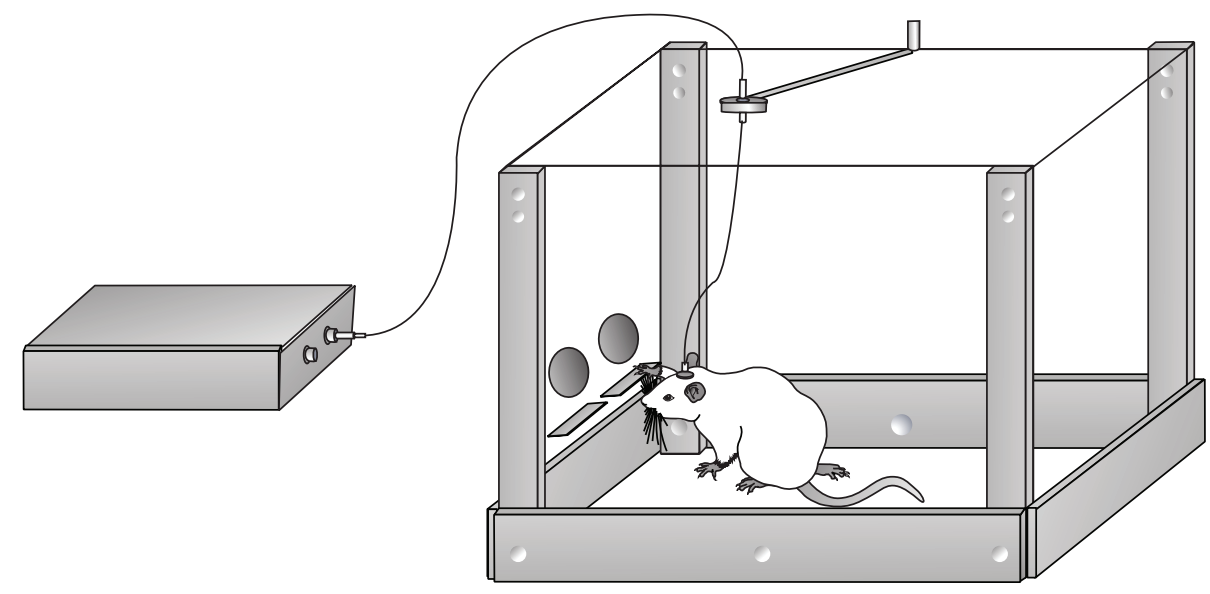

FIGURE 3: The ICSS paradigm for assessment of the ability of synthetic cathinones to affect brain reward function. Upon pressing of one of two levers (designated the active lever) in an operant self-administration chamber (right), a computer-controlled current generator (left) delivers pulses of electrical current to an indwelling bipolar electrode implanted into the MFB. Current can be delivered to the electrode at various intensities and frequencies in a variety of paradigms involving multiple trials in order to determine baseline and drug-induced shifts in current intensity thresholds or frequency response curves. See text for further details.

begins where each trial is initiated with a "free" (nonresponse contingent) stimulation, followed by an intertrial interval (ITI, average $7.5 \mathrm{sec}$ ) where responses yield no programmed consequences. After the ITI, an operant response yields stimulation identical to the free stimulation. Once animals learn to inhibit responding during the ITI, baseline current intensity threshold training begins. These procedures begin at a predetermined level of current intensity (i.e., $120 \mu \mathrm{A}$ ). Trials are conducted in blocks ( 3 to 5 trials each), consisting of a free stimulation, ITI, and response-contingent stimulation and current intensity that remain the same for the entire block. Correct responding on the majority of trials results in a lowering of the current intensity by a fixed increment (e.g., $5 \mu \mathrm{A}$ ) for the next block of trials, whereas failure to correctly respond to most trials results in an increase in the current intensity by the same increment for the next trial block. This stimulation titration procedure progresses through 2 ascending and 2 descending series of current intensities. Across these 2 ascending and descending series, ICSS thresholds are calculated as the mean (in $\mu \mathrm{A}$ ) across blocks that do or do not support responding. Thus, ICSS thresholds represent the minimum current intensity at which the animal will reliably respond for electrical stimulation of the MFB. Following stabilization of ICSS thresholds across several days of testing, a dose of a candidate drug of abuse (such as a synthetic cathinone) is administered prior to a test session. In our laboratory, we assess changes in current intensity thresholds across a range of doses of each drug in a semirandom counterbalanced design, with multiple determinations at each dose to provide increased reliability of changes in current threshold intensities (see $[46,47,51]$ for details). Resulting decreases in ICSS thresholds (relative to baseline or saline administration) are indicative of hedonic rewarding effects of the drug (i.e., less current is required to activate the reward circuitry due to prior activation by the drug administered), whereas elevations in ICSS thresholds are indicative of aversive or dysphoric effects (i.e., more current is required to activate the reward circuitry due to the aversive nature of the drug administered). ICSS procedures have been used for over 50 years and have consistently revealed that nearly all drugs that are abused by humans, including psychostimulants, lower ICSS thresholds [51, 71, 74-76].

We have recently assessed the ability of acute systemic administration of the "first generation" synthetic cathinones MDPV [47] and methylone [46] to alter ICSS thresholds in laboratory rats. For MDPV, we found that all doses tested $(0.1,0.5,1$, and $2 \mathrm{mg} / \mathrm{kg})$ produced significant reductions in ICSS thresholds ( 20-40\%) compared with those following saline administration, with the most robust effects observed after the $1 \mathrm{mg} / \mathrm{kg}$ dose. We observed far less robust effects following administration of methylone, with doses of 0.1 and $0.5 \mathrm{mg} / \mathrm{kg}$ producing no effects on ICSS thresholds, whereas higher doses $(1,3,5$, and $10 \mathrm{mg} / \mathrm{kg})$ produced reductions in ICSS thresholds ranging from $\sim 5$ to $15 \%$ in parallel with increasing doses. These less robust effects of methylone versus MDPV on ICSS thresholds indicate that methylone may be less potent in activating brain reward circuit function, which could be attributable to its higher affinity for serotonin versus dopamine transporters $[32,38]$ and is likely related to the lack of escalated intake in extended access during self-administration. This reduced activation of brain reward circuitry by methylone, as compared to classical psychostimulants such as methamphetamine, has also been observed following administration of MDMA [78], the amphetamine analog of methylone, which also possesses a similar 5-HT/DA transporter affinity ratio [32].

We have also recently conducted a study on the potential ICSS threshold-lowering effects of the "second generation" synthetic cathinones $\alpha$-PVP and 4-MEC [79]. When rats were administered $\alpha$-PVP $(0.1,0.3,1$, or $5 \mathrm{mg} / \mathrm{kg})$, significant 
reductions $(\sim 14-20 \%)$ in ICSS thresholds were observed following the 0.3 and $1 \mathrm{mg} / \mathrm{kg}$ doses. When rats were administered 4-MEC $(0.3,1,3,10,30$, or $100 \mathrm{mg} / \mathrm{kg})$, significant reductions $(\sim 10-15 \%)$ in ICSS thresholds were observed following the 10 and $30 \mathrm{mg} / \mathrm{kg}$ doses. However, for both drugs, the highest doses tested produced increases ( $19 \%$ for $\alpha$-PVP at $5 \mathrm{mg} / \mathrm{kg}$ and $\sim 28 \%$ for 4 -MEC at $100 \mathrm{mg} / \mathrm{kg}$ ) in ICSS thresholds, suggesting aversive effects of these high doses. Our ICSS studies confirm reports by other laboratories that synthetic cathinones activate brain reward circuitry [80, 81].

\section{Conclusions and Future Directions}

We have demonstrated that laboratory rats will voluntarily self-administer the "first generation" synthetic cathinones MDPV and methylone via the intravenous route. Furthermore, MDPV, but not methylone, leads to escalation of intake following extended access to the drug. We also have demonstrated that MDPV and methylone, as well as the "second generation" synthetic cathinones $\alpha$-PVP and 4-MEC, lower current intensity thresholds for ICSS, indicating activation of brain reward circuitry. Along with existing case reports and preliminary epidemiological studies in humans [1-12], these findings clearly indicate that synthetic cathinones possess a significant abuse liability and potential for addiction and should be considered an emerging class of abused drugs that warrant appropriate legislative control and the development of interventions for detoxification and treatment.

However, numerous questions regarding the effects of synthetic cathinones on the brain still remain to be answered. For example, do synthetic cathinones possess affinity for any molecular entities other than monoamine transporters which might contribute to their neurobiological or behavioral effects? What are the mechanisms underlying the persistent psychotomimetic effects of synthetic cathinones? What is the feasibility of utilizing cognitive-behavioral, pharmacological, or other approaches for treating dependence on synthetic cathinones? What are the lasting effects of synthetic cathinones on neuronal plasticity and function, gliotransmission, cerebrovascular function, cell viability, gene expression, and epigenetic processes? Answers to this latter question are being actively pursued by our laboratory. Specifically, we are currently conducting studies on the effects of synthetic cathinone self-administration on macrostructural changes and neurotoxicity in the brain, with the ultimate goal of identifying potential mechanisms and treatment avenues for reversing lasting deleterious effects of synthetic cathinones in the brain. The field of synthetic cathinone research is only in its infancy, and while initial legislative efforts have attempted to curb the availability and use of these drugs of abuse, it is clear that many more "designer drugs" of this drug class (and others) will continue to evolve numerous steps ahead of policymakers, scientists, educators, and treatment professionals alike.

\section{Conflict of Interests}

The authors declare that there is no conflict of interests regarding the publication of this paper.

\section{Acknowledgment}

The authors wish to acknowledge Public Health Service Grant R01DA025606 from National Institute on Drug Abuse for supporting their initial studies on synthetic cathinone abuse potential.

\section{References}

[1] M. H. Baumann, J. S. Partilla, and K. R. Lehner, "Psychoactive "bath salts": not so soothing," European Journal of Pharmacology, vol. 698, no. 1-3, pp. 1-5, 2013.

[2] M. Capriola, "Synthetic cathinone abuse," Clinical Pharmacology: Advances and Applications, vol. 5, pp. 109-115, 2013.

[3] J. A. Fass, A. D. Fass, and A. S. Garcia, "Synthetic cathinones (bath salts): legal status and patterns of abuse," Annals of Pharmacotherapy, vol. 46, no. 3, pp. 436-441, 2012.

[4] S. Gibbons, "Legal highs' novel and emerging psychoactive drugs: a chemical overview for the toxicologist," Clinical Toxicology, vol. 50, no. 1, pp. 15-24, 2012.

[5] C. Hall, C. Heyd, C. Butler, and M. Yarema, "'Bath salts' intoxication: a new recreational drug that presents with a familiar toxidrome," Canadian Journal of Emergency Medicine, vol. 16, no. 2, pp. 171-176, 2013.

[6] L. A. Johnson, R. L. Johnson, and R.-B. Portier, "Current 'legal highs," Journal of Emergency Medicine, vol. 44, no. 6, pp. 11081115, 2013.

[7] P. Mas-Morey, M. H. M. Visser, L. Winkelmolen, and D. J. Touw, "Clinical toxicology and management of intoxications with synthetic cathinones (bath salts)," Journal of Pharmacy Practice, vol. 26, no. 4, pp. 353-357, 2013.

[8] J. C. Maxwell, "Psychoactive substances—some new, some old: a scan of the situation in the U.S.," Drug and Alcohol Dependence, vol. 134, pp. 71-77, 2014.

[9] J. M. Prosser and L. S. Nelson, "The toxicology of bath salts: a review of synthetic cathinones," Journal of Medical Toxicology, vol. 8, no. 1, pp. 33-42, 2012.

[10] G. S. Winder, N. Stern, and A. Hosanagar, "Are "Bath salts" the next generation of stimulant abuse?" Journal of Substance Abuse Treatment, vol. 44, no. 1, pp. 42-45, 2013.

[11] J. B. Zawilska and J. Wojcieszak, "Designer cathinones-an emerging class of novel recreational drugs," Forensic Science International, vol. 231, no. 1-3, pp. 42-53, 2013.

[12] E. W. Gunderson, M. G. Kirkpatrick, L. M. Willing, and C. P. Holstege, "Substituted cathinone products: a new trend in "bath salts" and other designer stimulant drug use," Journal of Addiction Medicine, vol. 7, no. 3, pp. 153-162, 2013.

[13] American Association of Poison Control Centers, Bath Salts Data, 2013.

[14] N. N. Al-Hebshi and N. Skaug, "Khat (Catha edulis) -an updated review," Addiction Biology, vol. 10, no. 4, pp. 299-307, 2005.

[15] J. Ramsey, P. I. Dargan, M. Smyllie et al., "Buying "legal" recreational drugs does not mean that you are not breaking the law," QJM, vol. 103, no. 10, pp. 777-783, 2010.

[16] D. Zuba and B. Byrska, "Prevalence and co-existence of active components of 'legal highs"' Drug Testing and Analysis, vol. 5, no. 6 , pp. 420-429, 2013. 
[17] J. Hillebrand, D. Olszewski, and R. Sedefov, "Legal highs on the Internet," Substance Use and Misuse, vol. 45, no. 3, pp. 330-340, 2010.

[18] I. Vardakou, C. Pistos, and C. Spiliopoulou, "Drugs for youth via Internet and the example of mephedrone," Toxicology Letters, vol. 201, no. 3, pp. 191-195, 2011.

[19] M. Coppola and R. Mondola, "3,4-Methylenedioxypyrovalerone (MDPV): chemistry, pharmacology and toxicology of a new designer drug of abuse marketed online," Toxicology Letters, vol. 208, no. 1, pp. 12-15, 2012.

[20] T. M. Brunt, A. Poortman, R. J. M. Niesink, and W. van den Brink, "Instability of the ecstasy market and a new kid on the block: mephedrone," Journal of Psychopharmacology, vol. 25, no. 11, pp. 1543-1547, 2011.

[21] P. Deluca, Z. Davey, O. Corazza et al., "Identifying emerging trends in recreational drug use; outcomes from the Psychonaut Web Mapping Project," Progress in Neuro-Psychopharmacology and Biological Psychiatry, vol. 39, no. 2, pp. 221-226, 2012.

[22] T. P. Freeman, C. J. A. Morgan, J. Vaughn-Jones, N. Hussain, K. Karimi, and H. V. Curran, "Cognitive and subjective effects of mephedrone and factors influencing use of a 'new legal high", Addiction, vol. 107, no. 4, pp. 792-800, 2012.

[23] K. Miotto, J. Striebel, A. K. Cho, and C. Wang, "Clinical and pharmacological aspects of bath salt use: a review of the literature and case reports," Drug and Alcohol Dependence, vol. 132, no. 1-2, pp. 1-12, 2013.

[24] T. Penders and S. Y. Saeed, "Synthetic cannabinoids and "bath salts" should be considered drugs of abuse," American Family Physician, vol. 85, no. 9, p. 852, 2012.

[25] E. A. Ross, G. M. Reisfield, M. C. Watson, C. W. Chronister, and B. A. Goldberger, "Psychoactive "bath salts" intoxication with methylenedioxypyrovalerone," American Journal of Medicine, vol. 125, no. 9, pp. 854-858, 2012.

[26] A. Slomski, "A trip on "bath salts" is cheaper than meth or cocaine but much more dangerous," Journal of the American Medical Association, vol. 308, no. 23, pp. 2445-2447, 2012.

[27] N. Sadeg, A. Darie, B. Vilamot, M. Passamar, B. Frances, and H. Belhadj-Tahar, "Case report of cathinone-like designer drug intoxication psychosis and addiction with serum identification," Addictive Disorders and their Treatment, vol. 13, no. 1, pp. 38-43, 2014.

[28] R. A. Glennon, "Bath salts, mephedrone, and methylenedioxypyrovalerone as emerging illicit drugs that will need targeted therapeutic intervention," Advances in Pharmacology, vol. 69, pp. 581-620, 2014.

[29] "Food and drug administration safety and innovation act," in Proceedings of the 112th Congress of the United States of America, S.3187, 2012.

[30] Drug Enforcement Administration, "Schedules of controlled substances: placement of methylone into Schedule I," 21 CFR Part 1308, Docket No. DEA-357, U.S. Department of Justice, 2013.

[31] Drug Enforcement Administration, "Schedules of controlled substances: temporary placement of 10 synthetic cathinones into Schedule I," 21 CFR Part 1308, Docket No. DEA-386, U.S. Department of Justice, 2014.

[32] M. H. Baumann, M. A. Ayestas Jr., J. S. Partilla et al., “The designer methcathinone analogs, mephedrone and methylone, are substrates for monoamine transporters in brain tissue," Neuropsychopharmacology, vol. 37, no. 5, pp. 1192-1203, 2012.

[33] K. Cameron, R. Kolanos, R. Verkariya, L. de Felice, and R. A. Glennon, "Mephedrone and methylenedioxypyrovalerone (MDPV), major constituents of "bath salts" produce opposite effects at the human dopamine transporter," Psychopharmacology, vol. 227, no. 3, pp. 493-499, 2013.

[34] K. N. Cameron, R. Kolanos, E. Solis Jr., R. A. Glennon, and L. J. de Felice, "Bath salts components mephedrone and methylenedioxypyrovalerone (MDPV) act synergistically at the human dopamine transporter," British Journal of Pharmacology, vol. 168, no. 7, pp. 1750-1757, 2013.

[35] G. C. Hadlock, K. M. Webb, L. M. McFadden et al., “4Methylmethcathinone (mephedrone): neuropharmacological effects of a designer stimulant of abuse," Journal of Pharmacology and Experimental Therapeutics, vol. 339, no. 2, pp. 530-536, 2011.

[36] A. Kaizaki, S. Tanaka, and S. Numazawa, "New recreational drug 1-phenyl-2-(1-pyrrolidinyl)-1-pentanone (alphaPVP) activates central nervous system via dopaminergic neuron," Journal of Toxicological Sciences, vol. 39, no. 1, pp. 1-6, 2014.

[37] R. Kolanos, E. J. Solis, F. Sakloth, L. J. de Felice, and R. A. Glennon, "Deconstruction' of the abused synthetic cathinone methylenedioxypyrovalerone (MDPV) and an examination of effects at the human dopamine transporter," ACS Chemical Neuroscience, vol. 4, pp. 1524-1529, 2013.

[38] R. Lõpez-Arnau, J. Martínez-Clemente, D. Pubill, E. Escubedo, and J. Camarasa, "Comparative neuropharmacology of three psychostimulant cathinone derivatives: butylone, mephedrone and methylone," British Journal of Pharmacology, vol. 167, no. 2, pp. 407-420, 2012.

[39] J. Martínez-Clemente, E. Escubedo, D. Pubill, and J. Camarasa, "Interaction of mephedrone with dopamine and serotonin targets in rats," European Neuropsychopharmacology, vol. 22, no. 3, pp. 231-236, 2012.

[40] P. C. Meltzer, D. Butler, J. R. Deschamps, and B. K. Madras, "1(4-Methylphenyl)-2-pyrrolidin-1-yl-pentan-1-one (pyrovalerone) analogues: a promising class of monoamine uptake inhibitors," Journal of Medicinal Chemistry, vol. 49, no. 4, pp. 1420-1432, 2006.

[41] L. D. Simmler, T. A. Buser, M. Donzelli et al., "Pharmacological characterization of designer cathinones in vitro," British Journal of Pharmacology, vol. 168, no. 2, pp. 458-470, 2013.

[42] J. C. Yohannan and J. S. Bozenko, "The characterization of 3,4-methylenedioxypyrovalerone (MDPV)," Microgram Journal, vol. 7, pp. 12-15, 2010.

[43] M. H. Baumann, J. S. Partilla, K. R. Lehner et al., "Powerful cocaine-like actions of 3,4-methylenedioxypyrovalerone (MDPV), a principal constituent of psychoactive "bath salts" products," Neuropsychopharmacology, vol. 38, no. 4, pp. 552562,2013

[44] L. Iversen, S. Gibbons, R. Treble, V. Setola, X.-P. Huang, and B. L. Roth, "Neurochemical profiles of some novel psychoactive substances," European Journal of Pharmacology, vol. 700, no. 13, pp. 147-151, 2013.

[45] L. D. Simmler, A. Rickli, M. C. Hoener, and M. E. Liechti, "Monoamine transporter and receptor interaction profiles of a new series of designer cathinones," Neuropharmacology, vol. 79, pp. 152-160, 2014. 
[46] L. R. Watterson, L. E. Hood, K. Sewalia et al., "The reinforcing effects of the methylone, a synthetic cathinone commonly found in 'bath salts"' Journal of Addiction Research \& Therapy, supplement 9, article 002, 2012.

[47] L. R. Watterson, P. R. Kufahl, N. E. Nemirovsky et al., "Potent rewarding and reinforcing effects of the synthetic cathinone 3,4methylenedioxypyrovalerone (MDPV).," Addiction Biology, vol. 19, pp. 165-174, 2014.

[48] S. H. Ahmed, "The science of making drug-addicted animals," Neuroscience, vol. 211, pp. 107-125, 2012.

[49] S. H. Ahmed, "Validation crisis in animal models of drug addiction: beyond non-disordered drug use toward drug addiction," Neuroscience and Biobehavioral Reviews, vol. 35, no. 2, pp. 172184, 2010.

[50] G. F. Koob, "Addiction is a reward deficit and stress surfeit disorder," Frontiers in Psychiatry, vol. 4, article 72, 2013.

[51] L. R. Watterson, E. Watterson, and M. F. Olive, "Abuse liability of novel "legal high" designer stimulants: evidence from animal models," Behavioural Pharmacology, vol. 24, no. 5-6, pp. 341$355,2013$.

[52] S. Schenk, "MDMA self-administration in laboratory animals: a summary of the literature and proposal for future research," Neuropsychobiology, vol. 60, no. 3-4, pp. 130-136, 2009.

[53] S. Schenk, D. Gittings, M. Johnstone, and E. Daniela, "Development, maintenance and temporal pattern of self-administration maintained by ecstasy (MDMA) in rats," Psychopharmacology, vol. 169, no. 1, pp. 21-27, 2003.

[54] S. Schenk, L. Hely, B. Lake, E. Daniela, D. Gittings, and D. C. Mash, "MDMA self-administration in rats: acquisition, progressive ratio responding and serotonin transporter binding," European Journal of Neuroscience, vol. 26, no. 11, pp. 3229-3236, 2007.

[55] B. M. Cawrse, B. Levine, R. A. Jufer et al., "Distribution of methylone in four postmortem cases," Journal of Analytical Toxicology, vol. 36, no. 6, pp. 434-439, 2012.

[56] P. N. Carbone, D. L. Carbone, S. D. Carstairs, and S. A. Luzi, "Sudden cardiac death associated with methylone use," American Journal of Forensic Medicine and Pathology, vol. 34, no. 1, pp. 26-28, 2013.

[57] J. M. Pearson, T. L. Hargraves, L. S. Hair et al., "Three fatal intoxications due to methylone," Journal of Analytical Toxicology, vol. 36, no. 6, pp. 444-451, 2012.

[58] B. J. Warrick, J. Wilson, M. Hedge, S. Freeman, K. Leonard, and C. Aaron, "Lethal serotonin syndrome after methylone and butylone ingestion," Journal of Medical Toxicology, vol. 8, no. 1, pp. 65-68, 2012.

[59] S. M. Aarde, D. Angrish, D. J. Barlow et al., "Mephedrone (4methylmethcathinone) supports intravenous self-administration in Sprague-Dawley and Wistar rats," Addiction Biology, vol. 18, no. 5, pp. 786-799, 2013.

[60] S. M. Aarde, P. K. Huang, K. M. Creehan, T. J. Dickerson, and M. A. Taffe, "The novel recreational drug 3,4methylenedioxypyrovalerone (MDPV) is a potent psychomotor stimulant: self-administration and locomotor activity in rats," Neuropharmacology, vol. 71, pp. 130-140, 2013.

[61] C. P. Motbey, K. J. Clemens, N. Apetz et al., "High levels of intravenous mephedrone (4-methylmethcathinone) selfadministration in rats: neural consequences and comparison with methamphetamine," Journal of Psychopharmacology, vol. 27, no. 9, pp. 823-836, 2013.

[62] R. A. Wise, P. Bauco, W. A. Carlezon Jr., and W. Trojniar, "Selfstimulation and drug reward mechanisms," Annals of the New York Academy of Sciences, vol. 654, pp. 192-198, 1992.

[63] G. F. Koob, "Drugs of abuse: anatomy, pharmacology and function of reward pathways," Trends in Pharmacological Sciences, vol. 13, no. 5, pp. 177-184, 1992.

[64] G. F. Koob and N. D. Volkow, "Neurocircuitry of addiction," Neuropsychopharmacology, vol. 35, no. 1, pp. 217-238, 2010.

[65] S. Jacques, "Brain stimulation and reward: "pleasure centers" after twenty-five years," Neurosurgery, vol. 5, no. 2, pp. 277-283, 1979.

[66] R. A. Wise and G. F. Koob, “The development and maintenance of drug addiction," Neuropsychopharmacology, vol. 39, pp. 254262, 2014.

[67] G. F. Koob, "Neural mechanisms of drug reinforcement," Annals of the New York Academy of Sciences, vol. 654, pp. 171-191, 1992.

[68] M. E. Olds and J. L. Fobes, "The central basis of motivation: intracranial self-stimulation studies," Annual Review of Psychology, vol. 32, pp. 523-574, 1981.

[69] E. L. Gardner, "Addiction and brain reward and antireward pathways," Advances in Psychosomatic Medicine, vol. 30, pp. 22 60, 2011.

[70] J. Olds, "A preliminary mapping of electrical reinforcing effects in the rat brain," Journal of Comparative and Physiological Psychology, vol. 49, no. 3, pp. 281-285, 1956.

[71] J. Olds, "Self-stimulation of the brain-its use to study local effects of hunger, sex, and drugs," Science, vol. 127, pp. 315-324, 1958.

[72] J. OLDS, "Hypothalamic substrates of reward," Physiological Reviews, vol. 42, pp. 554-604, 1962.

[73] J. Olds and P. Milner, "Positive reinforcement produced by electrical stimulation of septal area and other regions of rat brain," Journal of Comparative and Physiological Psychology, vol. 47, no. 6, pp. 419-427, 1954.

[74] S. Vlachou and A. Markou, "Intracranial self-stimulation," in Animal Models of Drug Addiction, M. C. Olmstead, Ed., vol. 53, pp. 3-56, Springer, New York, NY, USA, 2011.

[75] W. A. Carlezon Jr. and E. H. Chartoff, "Intracranial selfstimulation (ICSS) in rodents to study the neurobiology of motivation," Nature Protocols, vol. 2, no. 11, pp. 2987-2995, 2007.

[76] C. Kornetsky, R. U. Esposito, S. McLean, and J. O. Jacobson, "Intracranial self-stimulation thresholds. A model for the hedonic effects of drugs of abuse," Archives of General Psychiatry, vol. 36, no. 3, pp. 289-292, 1979.

[77] A. Markou and G. F. Koob, "Construct validity of a selfstimulation threshold paradigm: effects of reward and performance manipulations," Physiology and Behavior, vol. 51, no. 1, pp. 111-119, 1992.

[78] C. B. Hubner, M. Bird, S. Rassnick, and C. Kornetsky, "The threshold lowering effects of MDMA (ecstasy) on brainstimulation reward," Psychopharmacology, vol. 95, no. 1, pp. 49$51,1988$.

[79] L. R. Watterson, R. Hernandez, K. N. Moore, M. Grabenauer, J. A. Marusich, and M. F. Olive, "Rewarding effects of $\alpha$ pyrrolidinovalerophenone ( $\alpha$-PVP) and 4-methylethcathinone 
(4-MEC), two synthetic cathinones commonly found in "second-generation" bath salts," Submitted to International Journal of Neuropsychopharmacology.

[80] C. Boulanger-Gobeil, M. St-Onge, M. Laliberté, and P. L. Auger, "Seizures and hyponatremia related to ethcathinone and methylone poisoning," Journal of Medical Toxicology, vol. 8, no. 1, pp. 59-61, 2012.

[81] J. E. Robinson, A. E. Agoglia, E. W. Fish, M. C. Krouse, and C. J. Malanga, "Mephedrone (4-methylmethcathinone) and intracranial self-stimulation in C57BL/6J mice: comparison to cocaine," Behavioural Brain Research, vol. 234, no. 1, pp. 76-81, 2012. 

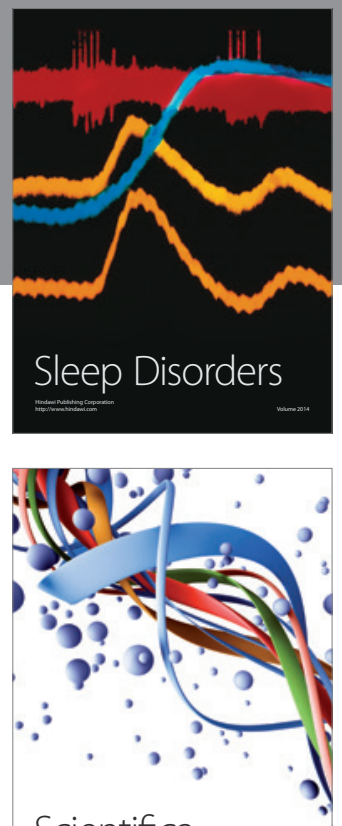

Scientifica
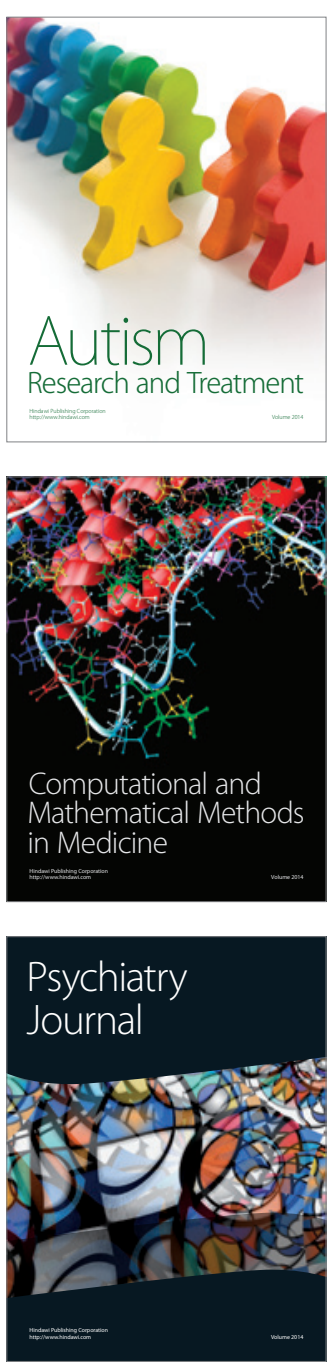
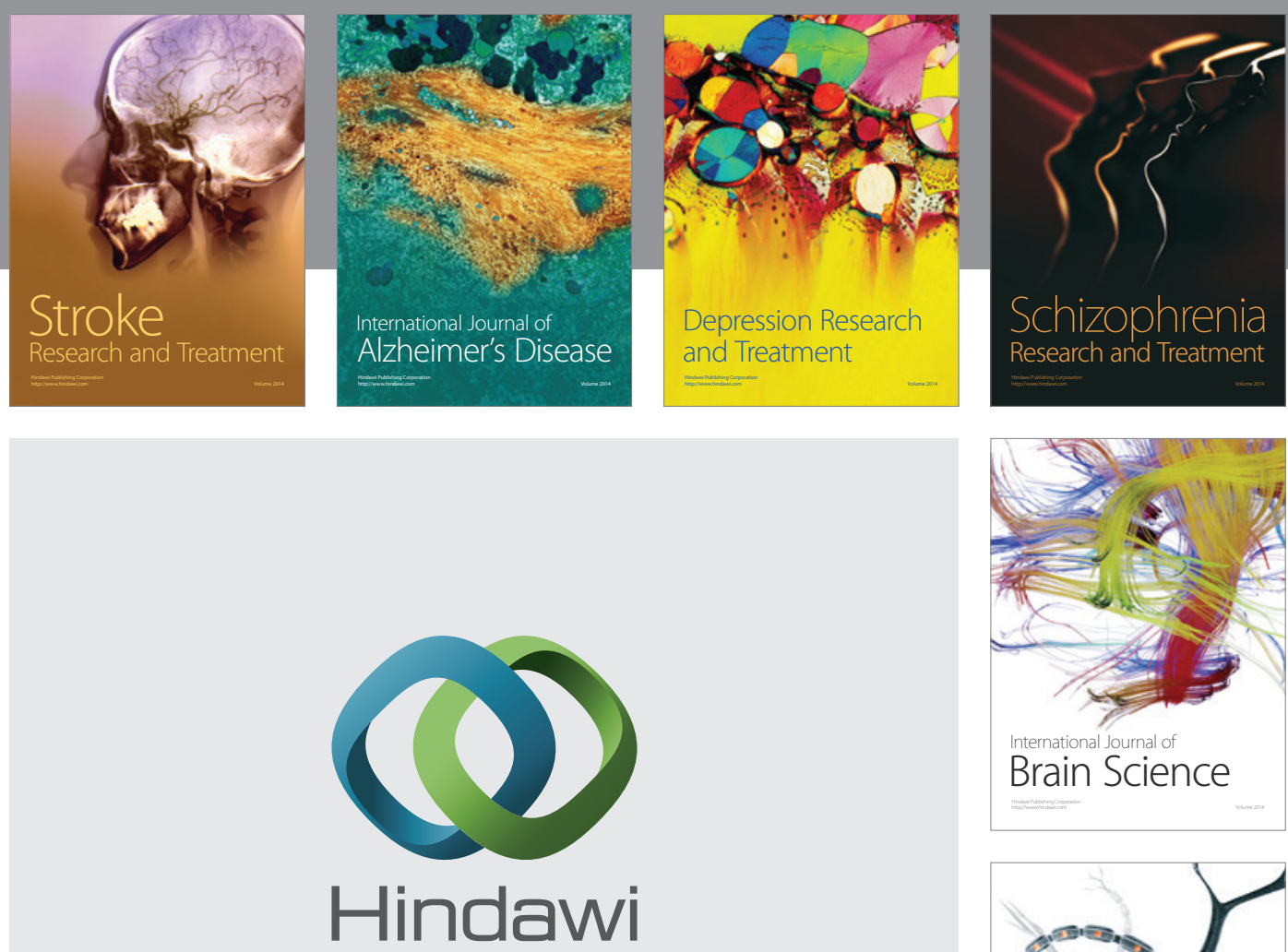

Submit your manuscripts at

http://www.hindawi.com
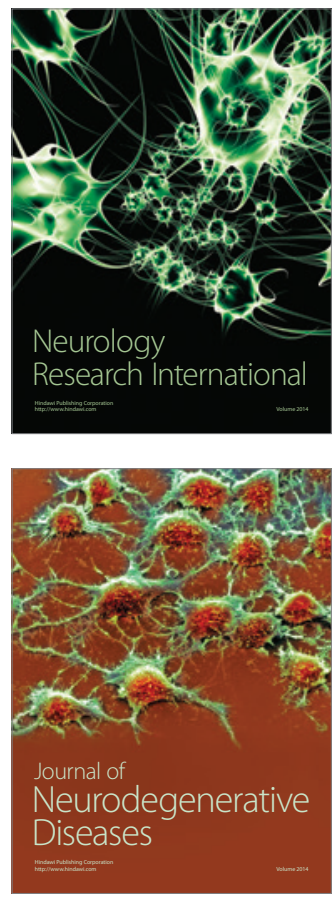

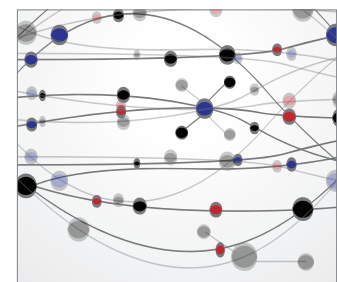

The Scientific World Journal
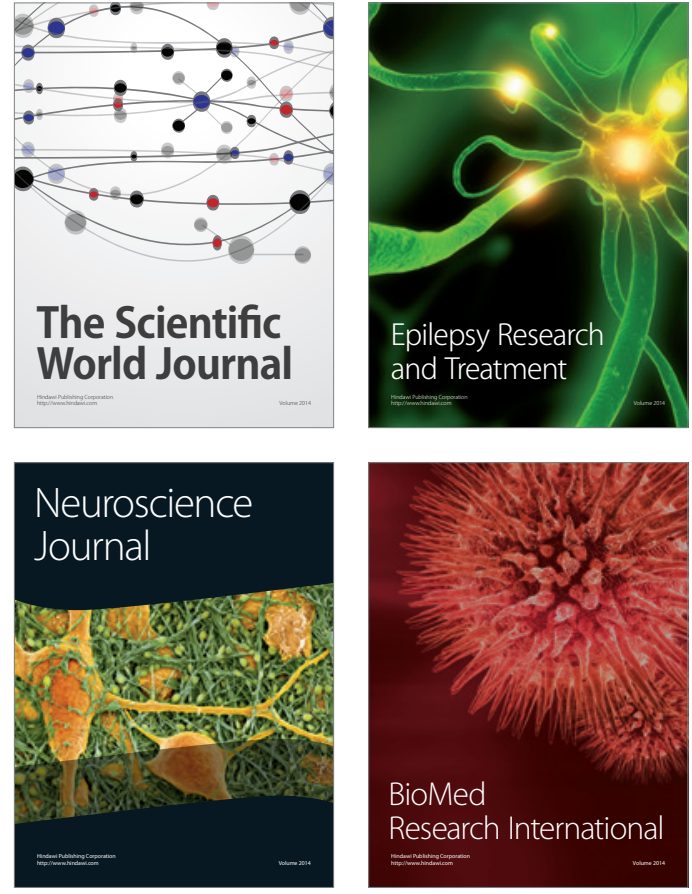

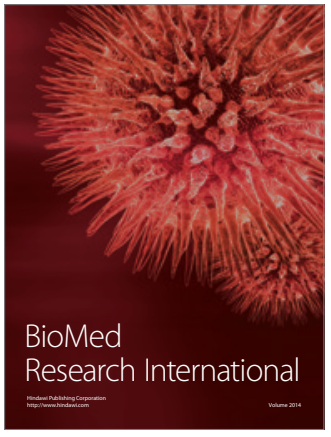

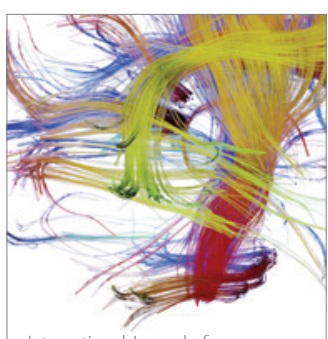

Brain Science

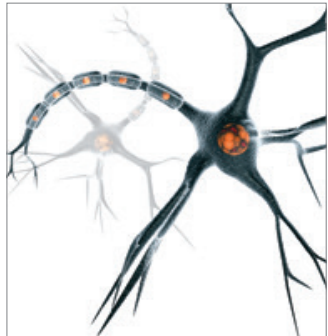

Neural Plasticity
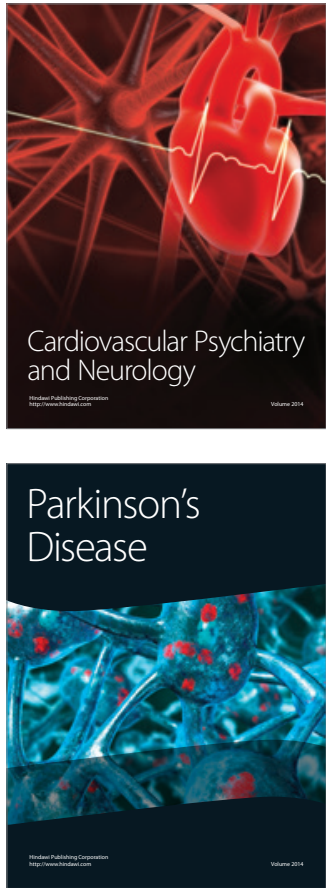